\title{
Quercetin: A Versatile Flavonoid
}

\author{
Dr. Parul Lakhanpal*, MD and Dr. Deepak Kumar Rai ${ }^{\dagger}$, MD \\ *Reader, Department of Pharmacology, SSR Medical College, Mauritius \\ ${ }^{\dagger}$ SMHO, Department of Pediatrics, Ministry of Health \& Quality of Life, Mauritius
}

(Received 04 January 2007 and accepted 29 March 2007)

\begin{abstract}
Associative evidence from observational and intervention studies in human subjects shows that a diet including plant foods (particularly fruit and vegetables rich in antioxidants) conveys health benefits. There is no evidence that any particular nutrient or class of bioactive substances makes a special contribution to these benefits. Flavonoids occur naturally in fruits, vegetables and beverages such as tea and wine. Quercetin is the major flavonoid which belongs to the class called flavonols. Quercetin is found in many common foods including apples, tea, onions, nuts, berries, cauliflower, cabbage and many other foods. Quercetin provides many health promoting benefits, including improvement of cardiovascular health, eye diseases, allergic disorders, arthritis, reducing risk for cancers and many more.

The main aim of this review is to obtain a further understanding of the reported beneficial health effects of Quercetin, its pharmacological effects, clinical application and also to evaluate its safety.
\end{abstract}

KEY WORDS: Quercetin, Flavonoid, Antioxidant, Health.

\section{INTRODUCTION:}

Quercetin is a unique bioflavonoid that has been extensively studied by researchers over the past 30 years. Bioflavonoids were first discovered by Nobel Prize laureate Albert Szent Gyorgyi in the year 1930. Flavonoids belong to a group of natural substances with variable phenolic structure and are found in the fruits, vegetables, grains, bark roots, stem, flowers, tea and wine ${ }^{1}$. These natural products were known for their beneficial effects on health long before flavonoids were isolated as the effective compounds. More than 4000 varieties of flavonoids have been identified, many of which are responsible for their attractive colors of flowers, fruits and leaves ${ }^{2}$.

Flavonoids occur as aglycones, glycosides and methylated derivatives. The flavonoid aglycone consists of a benzene ring (A) condensed with a six membered ring $(C)$, which in the 2-position carries a phenyl ring (B) as a substituent ${ }^{3}$. The Flavonoids can be divided into various classes on the basis of their molecular structures (Figure 1) ${ }^{4}$.

Six-member ring condensed with the benzene ring is either a-pyrone (flavonols and flavonones) or its dihydroderivative (flavanols and flavanones). The position of the benzenoid substituent divides the flavonoid class into flavonoids (2-position) and isoflavonoids (3position). Flavonols differ from flavonones by hydroxyl group the 3-position and $\mathrm{C} 2-\mathrm{C} 3$ double bonds ${ }^{5}$. Flavonoids are often hydroxylated in position 3, 5, 7, 2', 3', 4', 5'. Methylethers and acetylesters of the alcohol group are known to occur in nature. When glycosides are formed, the glycosidic linkage is normally located in positions 3 or 7 and the carbohydrate can be Lrhamnose, D-glucose, glucor-hamnose, galactose or arabinose ${ }^{6}$. Flavonoids are mainly divided into seven major groups (figure-2) ${ }^{7}$. One of the best described flavonoids, Quercetin is a member of this group.

Corresponding Author: Dr. Parul Lakhanpal, Reader, Department of Pharmacology, SSR Medical College, Belle-Rive, Mauritius, Email: lakhanpalparul@rediffmail.com 
<smiles>O=c1c(O)c(-c2ccccc2)oc2ccccc12</smiles>

Flavonol<smiles>Oc1cc(O)c2c(c1)O[C@H](c1ccc(O)c(O)c1)[C@H](O)C2</smiles>

Flavanol (Catechins)<smiles>O=c1cc(-c2ccccc2)oc2ccccc12</smiles>

Flavone<smiles>O=c1c(-c2ccccc2)coc2ccccc12</smiles>

Isoflavone<smiles>O=C1CC(c2ccccc2)Oc2ccccc21</smiles>

Flavanone

Figure 1: Structures of the major classes of Flavonoid ${ }^{4}$

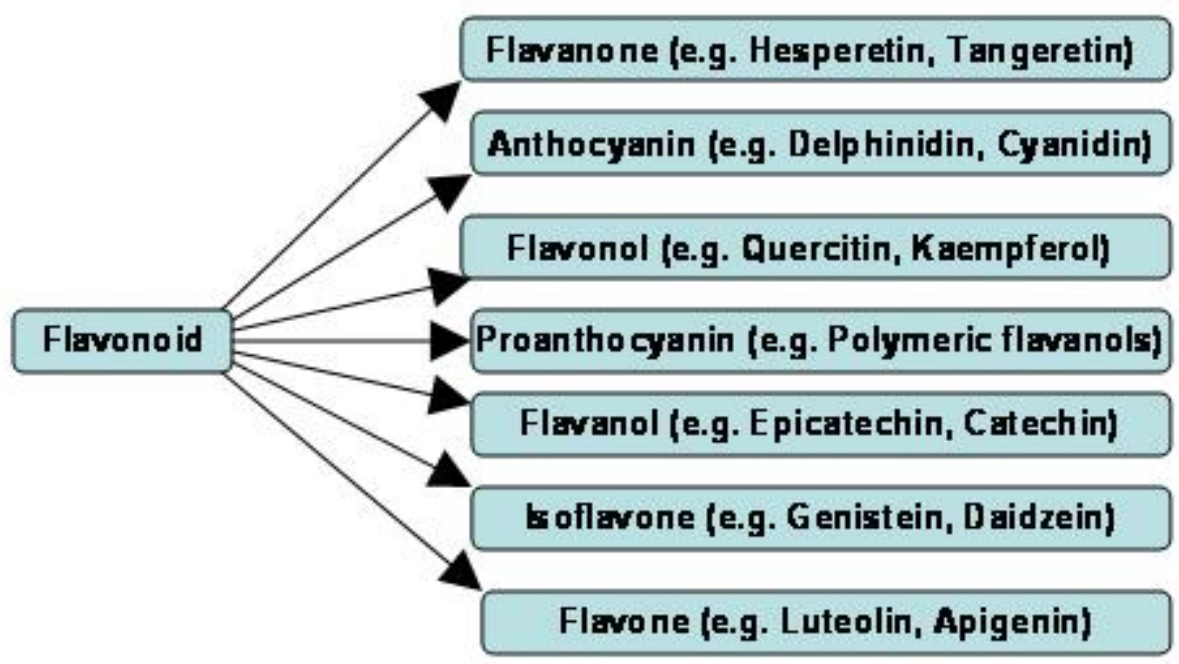

Figure 2: Major classes of Flavonoids ${ }^{7}$

Quercetin is found in abundance in onions, broccoli, apples and berries. The second group is flavanones, which are mainly found in citrus fruits. An example of a Flavonoid in this group is naringinin. Flavonoids belonging to the catechins are mainly found in green and black tea and in red wine, whereas, anthocyanins are found in strawberries, other berries, grapes, wines and tea ${ }^{2}$. Flavonoid contents of different foods are shown in Table-1. 
Table 1: Main groups of flavonoids, compounds and food sources

\begin{tabular}{|c|c|c|}
\hline Groups & Compounds & Food sources \\
\hline Flavonols & $\begin{array}{l}\text { Quercetin } \\
\text { Kaempferol } \\
\text { Myricetin } \\
\text { Isorhamnetin } \\
\text { Querctagetin }\end{array}$ & $\begin{array}{l}\text { Yellow onion, Curly kale, } \\
\text { Leek, Cherry tomato, } \\
\text { Broccoli, Apple, Green and } \\
\text { black tea, Black grapes, } \\
\text { Blueberry. }\end{array}$ \\
\hline Flavones & $\begin{array}{l}\text { Tangeretin } \\
\text { Heptamethoxyflavone } \\
\text { Nobiletin } \\
\text { Sinensetin } \\
\text { Quercetogetin } \\
\text { Chrysin } \\
\text { Apegenin } \\
\text { Luteolin } \\
\text { Disometin } \\
\text { Tricetin } \\
\end{array}$ & $\begin{array}{l}\text { Parsley, Celery, Capsicum } \\
\text { pepper. }\end{array}$ \\
\hline Flavanones & $\begin{array}{l}\text { Naringenin } \\
\text { Eriodictyol } \\
\text { Hesperetin } \\
\text { Dihydroquercetin } \\
\text { Dihydrofisetin } \\
\text { Dihydrobinetin } \\
\end{array}$ & $\begin{array}{l}\text { Orange juice, Grapefruit } \\
\text { juice, Lemon juice. }\end{array}$ \\
\hline Flavanols & $\begin{array}{l}\text { Silibinin } \\
\text { Silymarin } \\
\text { Taxifolin } \\
\text { Pinobanksin }\end{array}$ & $\begin{array}{l}\text { Cocoa, Cocoa beverages, } \\
\text { Chocolates. }\end{array}$ \\
\hline $\begin{array}{c}\text { Catechins } \\
\text { (Proanthocyanidins) }\end{array}$ & $\begin{array}{l}\text { (+) Catechin } \\
\text { Gallocatechin } \\
\text { (-) Epicatechin } \\
\text { Epigallocatechin } \\
\text { Epicatechin 3-gallate } \\
\text { Epigallocatechin 3-gallate }\end{array}$ & $\begin{array}{l}\text { Chocolate, Beans, Apricot, } \\
\text { Cherry, Grapes, Peach, Red } \\
\text { wine, Cider, Green tea, Black } \\
\text { tea, Blackberry. }\end{array}$ \\
\hline Isoflavones & $\begin{array}{l}\text { Daidzein } \\
\text { Genistein } \\
\text { Glycitein }\end{array}$ & $\begin{array}{l}\text { Soy cheese, Soy flour, Soy } \\
\text { bean, Tofu. }\end{array}$ \\
\hline Anthocyanins & $\begin{array}{l}\text { Cyanidin } \\
\text { Delphinidin } \\
\text { Malvidin } \\
\text { Pelargonidin } \\
\text { Peonidin } \\
\text { Petunidin } \\
\end{array}$ & $\begin{array}{l}\text { Blue berry, Blackcurrant, } \\
\text { Black grapes, Cherry, } \\
\text { Rhubarb, Plum, Strawberry, } \\
\text { Red wine, Red cabbage. }\end{array}$ \\
\hline
\end{tabular}

Quercetin, the most abundant of the flavonoids (the name comes from the Latin-quercetum, meaning oak forest, quercus oak) consists of 3 rings and 5 hydroxyl groups (Figure-3) ${ }^{\mathbf{8}}$. Quercetin is a member of the class of flavonoids called flavonoles and forms the backbone for many other flavonoids including the citrus flavonoids like rutin, hesperidins, Naringenin and tangeritin. It is widely distributed in the plant kingdom in rinds and barks. Quercetin itself is an aglycon or aglucone that does not possess a carbohydrate moiety in its structure. 
Quercetin is typically found in plants as glycone or carbohydrate conjugates. Quercetin glycone conjugates include rutin and thujin. Rutin is also known as Quercetin-3-rutinoside.Thujin is also known as quercitrin, Quercetin-3-L-rhamnoside and 3-rhannosyl qurcetin. Onions contain conjugates of Quercetin and carbohydrate iso rhamnetin including Quercetin-3-4'-di-o-beta glucoside, isorhamnetin-4'-o-beta glucoside and Quercetin-4'-o-beta glucoside.

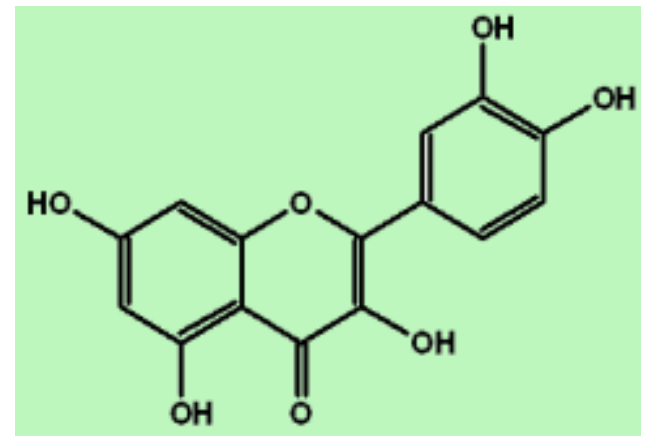

Figure-2 Molecular structure Quercetin ${ }^{8}$

\section{MECHANISM OF ACTION:}

Anti-oxidative action:

The best described property of Quercetin is its ability to act as antioxidant. Quercetin seems to be the most powerful flavonoids for protecting the body against reactive oxygen species, produced during the normal oxygen metabolism or are induced by exogenous damage ${ }^{\mathbf{9 , 1 0}}$. One of the most important mechanisms and the sequence of events by which free radicals interfere with the cellular functions seem to be the lipid peroxidation leading eventually the cell death. To protect this cellular death to happen from reactive oxygen species, living organisms have developed antioxidant line of defense systems ${ }^{11}$. These include enzymatic and nonenzymatic antioxidants that keep in check ROS/RNS level and repair oxidative cellular damage. The major enzymes, constituting the first line of defence, directly involved in the neutralization of ROS/RNS are: superoxide dismutase (SOD), catalase (CAT) and glutathione peroxidase (GPx) The second line of defence is represented by radical scavenging antioxidants such as vitamin $\mathrm{C}$, vitamin $\mathrm{A}$ and plant phytochemicals including quercetin that inhibit the oxidation chain initiation and prevent chain propagation. This may also include the termination of a chain by the reaction of two radicals. The repair and de novo enzymes act as the third line of defence by repairing damage and reconstituting membranes. These include lipases, proteases, DNA repair enzymes and transferases ${ }^{12}$.

\section{Direct radical scavenging action:}

Free radical production in animal cells can either be accidental or deliberate. With the increasing acceptance of free radicals as common place and important biochemical intermediates, they have been implicated in a large number of human diseases $^{\mathbf{1 3 , 1 4}}$. Quercetin acting as free radical scavengers was shown to exert a protective effect in reperfusion ischemic tissue damage ${ }^{15,16,17}$. Quercetin prevents free radical induced tissue injury by various ways. One way is the direct scavenging of free radicals. By scavenging free radicals, Flavonoid; particularly Quercetin can inhibit LDL oxidation in vitro ${ }^{\mathbf{1 8}}$. This action protects against atherosclerosis.

\section{Inducible nitric oxide syntheses Inhibitory action:}

Quercetin results in a reduction in ischemia reperfusion injury by interfering with inducible nitric oxide synthase activity ${ }^{19}$. Nitric oxide is produced by several different types of cells including endothelial cells and macrophages. Although the early release of nitric oxide through the activity of constitutive nitric oxide synthase is important in maintaining the dilatation of blood vessels ${ }^{20}$, the much higher concentration of nitric oxide produced by inducible nitric oxide synthase in macrophages can result in oxidative damage. In these circumstances the activated macrophages greatly increase their simultaneous production of both nitric oxide and superoxide anions. Nitric oxide reacts with free radicals, thereby producing high damaging peroxynitrite. Peroxynitrite can directly oxidize LDLs resulting in irreversible damage to cell membranes. Quercetin causes scavenging of free radicals; therefore can no longer react with nitric oxide, resulting in less damage ${ }^{21}$. Nitric oxide interestingly can be viewed as radical itself and can directly be scavenged by Flavonoids ${ }^{22}$.

\section{Xanthine oxidase inhibitory action:}

The xanthine oxidase pathway has been implicated as an important route in the oxidative injury to the tissues especially after ischemiareperfusion ${ }^{23}$. Both xanthine dehydrogenase and xanthine oxidase are involved in the metabolism of xanthine to uric acid. Xanthine dehydrogenase is the form of the enzyme present under physiological condition but its configuration changed to xanthine oxidase during oxidative 
stress and ischemic conditions. Quercetin seems to inhibit xanthine oxidase activity thereby resulting in decreased oxidative injury ${ }^{19,24,25}$.

\section{Decreasing Leukocyte immobilization:}

The immobilization and the firm adhesions of leukocytes to the endothelial wall is another major mechanism responsible not only for the formation of oxygen derived free radicals but also for the release of cytotoxic oxidants and inflammatory mediators and further activation of complement system. Under normal conditions leukocytes move freely along the endothelial walls. However during ischemia and inflammation, various factors mainly endothelial derived mediators and complement factors may cause adhesions of the leukocytes to the endothelial walls, thereby immobilizing them and stimulating degranulation of neutrophils. As a result oxidants and inflammatory mediators are released, resulting in injury to the tissues. Oral administration of purified micronized flavonoids fraction was reported to decrease the number of immobilized leukocytes during reperfusion, which may be related to its protective mechanism against inflammatory conditions ${ }^{26}$.

\section{Modulation of gene expression:}

Recent studies indicate that the radical scavenger property of Quercetin is unlikely to be the sole explanation for their neuroprotective capacity and in fact, a wide spectrum of cellular signaling events may well account for their biological actions ${ }^{27}$.

Much recent interest has focused on the potential of Quercetin to interact with intracellular signaling pathways such as with the mitogenactivated protein kinase cascade. The strong neurotoxic potential of quercetin in primary cortical neurons may occur via specific and sensitive interactions within neuronal mitogenactivated protein kinase and $\mathrm{Akt} /$ protein kinase $\mathrm{B}$ (PKB) signaling cascades, both implicated in neuroal apoptosis. Quercetin induced potent inhibition of both Akt/PKB and ERK phosphorylation, resulting in reduced phosphorylation of BAD and a strong activation of caspase- $3^{27}$.

Tumor necrosis factor alpha (TNF- $\alpha$ ) is one of the major proinflammatory cytokines involved in the pathogenesis of chronic inflammatory diseases and is modulated by oxidative stress ${ }^{28,29}$. TNF- $\alpha$ also triggers the cellular release of other cytokines, chemokines, or inflammatory mediators and displays antiviral and antimicrobial effects $^{30,31,32}$. Quercetin significantly inhibited TNF- $\alpha$ production and gene expression in a dose-dependent manner. A decrease in endogenous TNF- $\alpha$ production in the presence of quercetin indicates that flavonoids have the capacity to modulate the immune response and have potential anti-inflammatory activity. In addition to its well-known proinflammatory role, TNF- $\alpha$ has complex effects on the growth, differentiation, and death of immune cells. TNF- $\alpha$ inhibition is a validated approach to treat several inflammatory diseases $^{\mathbf{2 8}}$. Quercetin-induced suppression of TNF- $\alpha$ can result in the stimulation of antiinflammatory cytokines via inhibiting the activation of $\mathrm{NF}-\kappa \beta$, and therefore, one can anticipate that quercetin could be widely used as an anti-TNF- $\alpha$ therapy. Kaneuchi et $\mathbf{a l}^{33}$ showed that quercetin has anti-proliferative activity and the mechanisms of quercetin action may be through modulation of cell cycle and cell growth regulatory genes. Quercetin can suppress proliferation of Ishikawa cells (endometrial carcinoma) through down-regulation of EGF and cyclin D1.

\section{Interaction with other enzyme systems:}

Quercetin interacts with calmodulin, a calcium regulatory protein ${ }^{34}$. Calmodulin transports calcium ion across cellular membranes, initiating numerous cellular process. Quercetin appears to act as calmodulin antagonist. Through this mechanism, Quercetin functions at cell membrane level with a membrane stabilizing action $^{35}$. Quercetin inhibits calmodulin dependent enzyme present at cell membrane such as ATPases and phospholipases thereby influencing membrane permeability ${ }^{36}$. Quercetin affects other calmodulin dependent enzymes that control various cellular functions, including the secretions of histamine from mast cells ${ }^{4}$. A number of investigations have demonstrated the ability of Quercetin, to reduce histamine secretion from mast cells in various tissues and also from basophils ${ }^{37-42}$. The enzyme inhibitory action of Quercetin extends to phospholipases which catalyses the release of arachidonic acid from phospholipids stored in cell membranes. Arachidonic acid serves as a key substrate for substances such as thromboxane, inflammatory prostaglandins and leukotrienes. In addition, Quercetin also inhibits the enzymes cyclooxygenase and Lipooxygenase which catalyses the conversion of arachidonic acid to its metabolites ${ }^{\mathbf{4 2 , 4 3 , 4 4}}$. Reducing levels of these metabolites as well as histamine levels, is beneficial in maintaining the normal comfort 
level of body tissue and structures. Quercetin has also been shown to limit the function of adhesion molecules on endothelial cells ${ }^{45}$. Quercetin also chelates ions of transition metals such as iron which can initiate the formation of oxygen free radicals ${ }^{\mathbf{4 6 , 4 7}}$. Direct inhibition of lipid peroxidation is another protective measures ${ }^{\mathbf{4 8}}$.

\section{PHARMACOKINETICS:}

The metabolism and pharmacokinetics of flavonoids has been an area of active research in the last decade. To date, approximately 100 studies have reported the pharmacokinetics of individual flavonoids in healthy volunteers. The data indicate considerable differences among the different types of dietary flavonoids so that the most abundant flavonoids in the diet do not necessarily produce the highest concentration of flavonoids or their metabolites in vivo. Small intestinal absorption ranges from 0 to $60 \%$ of the dose and elimination half-life $\left(T_{1 / 2}\right)$ range from 2 to $28 \mathrm{~h}^{49}$

Quercetin is generally believed to be poorly absorbed. About $25 \%$ of an injected dose of quercetin is absorbed from small intestine. Although a recent study by Hollman et al concludes that humans absorb appreciable amount of quercetin, contradicts the assumption $^{\mathbf{5 0}}$. However, it is found in human plasma as conjugates with glucuronic acid, sulfate or methyl groups, with no significant amounts of free quercetin. Quercetin was found to reach $0.1-10 \mu \mathrm{mol} / \mathrm{lit}$ (micromole per liter) in the circulation. The concentration of quercetin was mainly due to the presence of quercetin metabolites rather than its aglycon as recently revised by Murota and Terao ${ }^{51}$. Regarding the pharmacokinetics of quercetin glucosides conjugates; it seems that the main determinant of absorption of these conjugates is the nature of the sugar moiety. For example quercetin glucoside is absorbed from small intestine, whereas quercetin rutinosides is absorbed from the colon after the removal of carbohydrate moiety by bacterial enzymes. In addition to the chemical form of the flavonol, the fat content of the diet also influences oral bioavailability of quercetin. Lesser et al investigated the influence of dietary fat on oral bioavailability of quercetin. According to the them, Quercetin bioavailability from each diet was always higher from the glucoside than from the aglycon but irrespective of the chemical form applied, the bioavailability of quercetin was also found to be higher in the $17 \%$ fat diet compared with the $3 \%$ fat diet $(\mathrm{P}<$ $0.05)^{52}$.
Studies have shown that Bromelain, an enzyme derived from pineapple, enhances the absorption of quercetin. Bromelain is a complex substance largely composed of proteolytic enzymes. Several studies have presented the evidence that bromelain is a fibrinolytic agent ${ }^{53,54}$. Bromelain is also known to have many of the same histamine and Leukotriene-inhibitory properties as quercetin. In this way they enhance each other properties.

After getting absorbed in small intestine, quercetin is transported to the liver via portal circulation, where it undergoes first pass metabolism. Quercetin and its metabolites are distributed to various tissues in the body. Quercetin is strongly bound to the albumin in plasma. Peak plasma level reaches in $0.7 \mathrm{~h}$ to 7.0 hours following its ingestion. The elimination half life of quercetin is approximately 25 hours ${ }^{55}$. The elimination of quercetin was significantly delayed after its application with fat-enriched $\operatorname{diets}(\mathrm{P}<0.05)^{52}$.

\section{ADVERSE DRUG REACTION:}

Adverse effects reported with oral quercetin include gastrointestinal effects such as nausea and rare reports of headache and mild tingling of the extremities. Oral quercetin is generally well tolerated. Intravenous quercetin has been associated with nausea, vomiting, diaphoresis, flushing, and dyspnoea.

\section{Safety Profile:}

There is much controversy regarding the purported toxic or even mutagenic properties of quercetin. Formica and Regelson gave an interesting overview of quercetin in vivo and in vitro $^{56}$. The early data on toxic side effects are mainly derived from in vitro studies. At a conference of the Federation of American societies for experimental biology in 1984 on mutagenic food flavonoids, carcinogenicity was reported in just one out of 17 feeding studies conducted in laboratory animals ${ }^{57,58}$. Dunnick and Hailey reported that high doses of quercetin over several years might result in the formation of tumors in mice ${ }^{59}$. However, back in the 1970 s, quercetin was found to have mutagenic activity as determined by the in vitro Ames test, which was developed by researcher Bruce Ames to test if a natural or synthetic substance will cause DNA mutations in bacteria ${ }^{\mathbf{6 0}}$. However in other long term study, no carcinogenicity was found ${ }^{\mathbf{6 1}}$. In contrast to earlier studies several more recent reports indicate that quercetin is antimutagenic in vivo $^{56,62,63}$. A large clinical study by Knekt et 
al, in which 9959 men and women were followed for 24 years, showed an inverse relationship between the intake of quercetin and lung cancer ${ }^{64}$. One possible explanation for these conflicting data is that quercetin is toxic to cancer cells or immortalized cells but not toxic to normal cells. In other studies quercetin was also recognized as genoprotective against mutagenic agents $^{65,66}$. Review of the total body of available data on quercetin as presented in several published reviews indicates that quercetin, although displaying mutagenic activity in vitro is not carcinogenic in the body. In a number of studies such as Formica and Regelson ${ }^{56}$, Stavric $^{58}$, Stoewsand ${ }^{67}$ and recently Okamoto $^{68}$, a review of quercetin safety based on past animal toxicity studies, concluded that orally administered quercetin is unlikely to cause any adverse effects although specific dose levels were not indicated.

\section{CONTRAINDICATIONS \\ PRECAUTIONS:}

Contraindication of Quercetin is not known. Quercetin has been shown to cause chromosomal mutations in certain bacteria in test tube studies. However the significance of this finding for humans is not clear Because of lack of the availability of long term safety data, quercetin should be avoided by pregnant women and nursing mothers.

\section{DRUG INTERACTIONS:}

Quercetin shows interaction with following drugs:

\section{Felodipine:}

Quercetin (found in grapefruit juice, tea, onions, and other foods) has been shown in test tube studies to inhibit enzymes responsible for breaking down of Felodipine into inactive forms. This interaction may result in increased blood levels of felodipine that could lead to unwanted side effects ${ }^{69}$. Until more is known about this interaction, patients taking felodipine should avoid supplementing with quercetin. Regular consumption of grapefruit juice can increase the quantity of felodipine in the blood by reducing the breakdown of the drug. The inhibitory effect of grapefruit juice lasts up to 24 hours after ingestion and can increase the blood levels nearly three times the expected amount. In order to prevent the side effects, individuals taking felodipine should avoid consuming grapefruits and its juice ${ }^{70}$.

\section{Estrogens:}

Studies have shown that grapefruit juice significantly increases estradiol levels in the blood $^{71,72}$. One of the flavonoids found in grapefruit juice is Quercetin. In a test tube study, quercetin was found to change estrogen metabolism in human liver cells in a way that it increases estradiol level and reduces other forms of estrogens ${ }^{72}$. However the levels of quercetin used to alter estrogen metabolism in the test tube were much higher than the levels found in the body after supplementing with quercetin.

In a small controlled study of women with surgically removed ovaries, estradiol levels in the blood were significantly higher after taking estradiol with grapefruit juice than when estradiol was taken alone ${ }^{71}$. These results have independently confirmed that women taking oral estradiol should probably avoid grapefruits altogether $^{72}$.

\section{Cyclosporine:}

In a randomized study of nine adults with cyclosporine treated auto-immune diseases, grapefruit juice causes a significant increase in cyclosporine blood levels compared with cyclosporine with water ${ }^{74}$. In another study by healthy human volunteers, supplementing quercetin along with cyclosporine significantly increased blood level of cyclosporine compared to when not taken quercetin ${ }^{75}$.

\section{Quinolones:}

Quercetin binds in vitro with DNA gyrase site in bacteria. Therefore theoretically it can serve as competitive inhibitor to the Quinolones, which also bind to the same site ${ }^{76}$.

\section{Cisplatin:}

Because of the theoretical risk of genotoxicity in normal tissues, in those using cisplatin along with quercetin, cisplatin users should avoid quercetin supplements.

\section{Doxorubicin:}

Test tube and animal studies suggest that quercetin may enhance the effect of doxorubicin.

\section{Digoxin:}

Treatment with both Digoxin and Quercetin may result in large amounts of digoxin in blood, which may cause more side effects of digoxin than usual. This interaction has been reported in animals, but how it affects people, is unclear ${ }^{\mathbf{8 0}}$.

\section{DIETARY SOURCES:}


Fruits and vegetables particularly citrus fruits, apples, onions, parsley, tea, red wine, etc. are the primary dietary sources of Quercetin. Olive oil, grapes, dark cherries, and dark berries such as blueberries and bilberries are also high in flavonoids including quercetin.

Studies were conducted on the Flavonoids (Myricetin, Quercetin, Kaempferol, Luteolin and Apegenin) contents of 62 edible tropical plants. The highest total flavonoids contents were found in onion leaves (1497 mg/Kg Quercetin, 391 $\mathrm{mg} / \mathrm{kg}$ Luteolin and $832 \mathrm{mg} / \mathrm{kg}$ Kaempferol) followed by semambu leaves, bird chillies, black tea, papaya shoots and guava. Major flavonoids content in these plant extract is quercetin, followed by myricetin, and kaempferol. In vegetables quercetin glycosides predominate but glycosides of kaempferol, luteolin and apigenin are also present. Fruits contain almost exclusively quercetin glycosides, whereas kaempferol and myricetin glycosides are found only in trace quantities ${ }^{\mathbf{7 8}}$. Table-2 shows contents of Quercetin, Myricetin and Kaempferol in selected food ${ }^{79}$.

Table 2: Amount of Quercetin in selected food ${ }^{79}$

\begin{tabular}{c|c|c|c}
\hline FOOD & $\begin{array}{c}\text { Quercetin } \\
\mathbf{m g} / \mathbf{1 0 0 g}\end{array}$ & $\begin{array}{c}\text { Myricetin } \\
\mathbf{m g} / \mathbf{1 0 0 g}\end{array}$ & $\begin{array}{c}\text { Kaempferol } \\
\mathbf{m g} / \mathbf{1 0 0 g}\end{array}$ \\
\hline Broccoli, Raw & 2.8 & 0.0 & 6.3 \\
\hline Carrots, Raw & 0.4 & 0.0 & 0.0 \\
\hline Celery, Raw & 3.5 & ---- & ---- \\
\hline Cocoa powder, Unsweetened & 20.1 & ---- & ---- \\
\hline Cranberries, Raw & 14.0 & 4.3 & 0.1 \\
\hline Kale, Raw & 5.1 & 0.0 & 14.6 \\
\hline Lettuce, Looseleaf, Raw & 2.0 & 0.0 & 0.0 \\
\hline Lingonberries, Raw & 11.3 & 0.0 & 0.0 \\
\hline Onions, Raw & 22.6 & 0.0 & 0.3 \\
\hline Tomatoes, Red ripe, Raw & 0.5 & 0.0 & 0.1 \\
\hline
\end{tabular}

In another study, content of quercetin was estimated in 25 edible berries. Sixteen species of cultivated berries and nine species of wild berries were collected in Finland in 1997. Quercetin was found in all the berries such as bog whortleberry (158 $\mathrm{mg} / \mathrm{kg}$ fresh weight), lingon berry (74 and $146 \mathrm{mg} / \mathrm{kg}$ ), cranberry (83 and $121 \mathrm{mg} / \mathrm{kg}$ ), chokeberry $(89 \mathrm{mg} / \mathrm{kg})$, sweet rowan $(85 \mathrm{mg} / \mathrm{kg})$, rowanberry $(63 \mathrm{mg} / \mathrm{kg})$, sea buckthorn berry $(62$ $\mathrm{mg} / \mathrm{kg}$ ) and crowberry (53 and $56 \mathrm{mg} / \mathrm{kg})^{\mathbf{8 0}}$.

Onions (Allium cepa L) ranked highest in quercetin content in a survey of 28 vegetables and 9 fruits $^{\mathbf{8 1}, 82}$. Quercetin levels tend to be highest in red and yellow onions and lowest in white onions ${ }^{\mathbf{8 3}, \mathbf{8 4}}$. Amount of quercetin in onions vary with bulb color type and variety. Regardless of onion bulb pigmentation, quercetin concentration is highest in the outer rings ${ }^{85,86}$.

However in another study, more than 60 fresh fruits, vegetables, and nuts were collected from four regions across the United States at two times of the year. Sample collection was designed and implemented by the Nutrient Data Laboratory (USDA), using a hydrolysis method for the anthocyanidins, flavones, and flavonols and a direct extraction method for the flavan-3ols and flavanones. This study showed that the variation in the flavonoid content of foods, as purchased by the U.S. consumer, is very large. The relative standard deviation, averaged for each flavonoid in each food, was $168 \%{ }^{87}$.

\section{THERAPEUTIC USES:}

Quercetin offers a variety of potential therapeutic uses primarily in the prevention and the treatment of the conditions listed below. Quercetin seems to work better when it is used in conjunction with bromelain, a digestive enzyme found in pineapple.

Allergies, asthma, hay fever and hives:

Quercetin might be useful in some of the allergies such as hay fever, hives. It inhibits the production and release of histamine and other allergic/inflammatory substances possibly by stabilizing cell membranes of mast cells ${ }^{\mathbf{8 6 , 8 8}}$. Mast cells have been proposed as an immune gate to the brain, as well as sensors of environmental and emotional stress, and are likely involved in neuropathologic processes 
such as multiple sclerosis. Among mast cell products, the protease tryptase could be associated with neurodegenerative processes through the activation of specific receptors (PARs) expressed in the brain, while interleukin (IL)-6 likely causes neurodegeneration and exacerbates dysfunction induced by other cytokines; or it could have a protective effect against demyelinisation. In the year 2006 a study conducted by Kempuraj et al showed that quercetin, a natural compound able to act as an inhibitor of mast cell secretion, causes a decrease in the release of tryptase and IL-6 and the downregulation of histidine decarboxylase (HDC) mRNA from human mast cell (HMC)-1. As quercetin dramatically inhibits mast cell tryptase, IL-6 release and HDC mRNA transcription by HMC-1 cell line, these results nominate quercetin as a therapeutical compound in association with other therapeutical molecules for neurological diseases mediated by mast cell degranulation $^{89}$.

\section{Antibacterial activity:}

Quercetin seems to exert antibacterial activity against almost all the strains of bacteria known to cause respiratory, gastrointestinal, skin and urinary disorders ${ }^{\mathbf{9 0}}$.

\section{Arthritis:}

Quercetin inhibits both cyclo-oxygenase and lipo-oxygenase activities thus diminishing the formation of inflammatory mediators ${ }^{91,92}$. In addition there are reports of people with rheumatoid arthritis, who experienced an improvement in their symptoms, when they switched from a typical western diet to a vegan diet with lots of uncooked berries, fruits, vegetables containing amongst other antioxidants, quercetin ${ }^{93}$.

\section{Cancers:}

Although the etiology of cancer may be multifactorial (e.g. diet, genetic, environment), there is wide recognition that reactive oxygen and nitrogen species (ROS/RNS) play a pivotal role in the pathophysiological process. ROS/RON have been shown to be carcinogenic and may exert their deleterious effects by causing DNA damage, alter cell signaling pathways (MAPK, NFkB, AP-1, PLA, ASK-1) and modulate gene expression (proto-oncogene, tumour suppressor gene). The evidence from in vitro and in vivo laboratory studies, clinical trials and epidemiological investigations show that plant-based diets have protective effects against various cancers. Indeed it has been suggested that about $7-31 \%$ of all cancers could be reduced by diets high in fruits and vegetables ${ }^{94}$.

In various animal and test tube studies, quercetin has been shown to inhibit the growth of cancer cells including those from breast, colon, prostate and lung cancers ${ }^{63}$. Quercetin by virtue of its anti-oxidant property prevents reactive oxygen species induced DNA damage, leading to mutational changes. A large clinical study suggested the presence of an inverse association between quercetin intake and subsequent incidence of lung cancers ${ }^{64}$. In the study done by Caltagirone et al, quercetin showed the inhibitory effect on the growth of melanoma and also influenced the invasive and metastatic potential in mice ${ }^{95}$. The bioflavonoid quercetin may be a potent alternative to reduce cisplatin induced nephrotoxicity ${ }^{\mathbf{9 6}}$. Furthermore quercetin seems to inhibit angiogenesis ${ }^{97}$. Angiogenesis is normally a strictly controlled process in the human body. Pathological, unregulated angiogenesis occurs in cancers ${ }^{98}$. Among the angiogenesis inhibitors quercetin seems to play an important role ${ }^{\mathbf{9 9}}$. However the mechanism behind the anti-angiogenic effect of flavonoids is unclear. A possible mechanism could be the inhibition of protein kinase ${ }^{\mathbf{1 0 0}}$. As many of the PTKs are oncogenes, this raised the possibility of quercetin being an effective anti-cancer compound. Quercetin was effective in inhibiting radiation-induced $\mathrm{PKC}$ activity. Activation of $\mathrm{PKC}$ is one of the means of conferring radioresistance on a tumour cell. Suppression of PKC activity by Quercetin may be one of the means of preventing the development of radioresistance following radiotherapy ${ }^{101}$.

\section{Coronary Heart Diseases:}

Anti-oxidant quercetin intake protects against coronary heart disease (CHD), caused by oxidized LDL (bad cholesterol). Hertog et al stated that regular consumption of flavonoids in the food might reduce the risk of deaths from CHD in elderly men ${ }^{\mathbf{1 0 2 , 1 0 3}}$. Furthermore a Japanese study reported an inverse correlation between quercetin intake and total plasma cholesterol concentration $^{104}$. Quercetin was also shown to be effective inhibitor of platelets aggregation in dogs and monkeys ${ }^{\mathbf{1 0 5}}$. The main antiplatelet aggregating effect is because of the inhibition of thromboxane $\mathrm{A} 2^{\mathbf{1 0 6}}$. Quercetin inhibits the proliferation and migration of aortic smooth muscle cells, and platelet aggregation along with the inhibition of mitogen-activated 
protein kinase phosphorylation. These findings provide new insights and a rationale for the potential use of quercetin in the prevention of cardiovascular diseases ${ }^{\mathbf{1 0 7}}$.

\section{Diabetic complications:}

Quercetin has been found to be an inhibitor of the enzyme aldose reductase, which plays a role in converting glucose (sugar) to sorbitol (a sugar alcohol) in the body. People with diabetes develop secondary problems, such as neuropathy, retinopathy, diabetic cataracts, and nephropathy because of sorbitol buildup in the body. Quercetin may therefore be beneficial in the nutritional management of diabetes, but clinical studies need to be conducted to verify these effects, which have been observed in nonhuman experiments ${ }^{\mathbf{1 0 8} .}$

\section{Eye disorders:}

Free radicals are thought to contribute the development of certain disorders including cataracts and macular degeneration. Quercetin prevents and treats these eye conditions by neutralizing these free radicals. In a study of 3,072 adults with the symptoms of macular degeneration, moderate red wine consumption (a source of quercetin) offered some protection against the development and the progression of the disease ${ }^{\mathbf{1 0 9}}$. Regular consumption of dark berries offers benefits for preventing macular degeneration $^{\mathbf{1 1 0}}$.

\section{Gout:}

Quercetin by virtue of its xanthine oxidase inhibitory nature prevents the production of uric acid, thereby easing the gout symptoms ${ }^{24,25}$.

\section{Neurodegenerative disorders:}

According to a study conducted by researchers at Cornell University in New York, a potent antioxidant (quercetin) in apples and in vegetables appear to protect brain cells against oxidative stress, a tissue damaging process associated with Alzheimer and other neurodegenerative disorders ${ }^{111}$. Quercetin seems to protect the brain functions by inhibiting the formation if fibrillated amyloid-beta, the senile plaque found in Alzheimer's brain ${ }^{106}$. An experiment was performed to demonstrate the possible effects of quercetin on cognitive performance of young and aged, ethanol intoxicated mice (animal model), where chronic quercetin treatment had shown the reversal of cognitive deficits ${ }^{\mathbf{1 1 2}}$. Even though quercetin is relatively stable during cooking, fresh apples are always better sources of quercetin than cooked or processed apples because the compound is mainly concentrated in the skin of apples. In general red apples tend have more of antioxidant than green or yellow ones. Quercetin, through its COMT and MAO enzymes inhibiting properties, might potentiate the anticatabolic effect of Ldopa plus carbidopa treatment. The results of the present study strongly suggest that quercetin could serve as an effective adjunct to L-dopa therapy in Parkinson disease ${ }^{113}$. Quercetin has potential for the treatment of neuroleptic-induced extrapyramidal side effects, such as from haloperidol $^{114}$. Quercetin also is a powerful antioxidant that may protect brain cells from damage.

\section{Osteoporosis:}

In an English study, bone mineral density was compared between elder women, who consumed tea and those who did not. Women in the study, who drank tea (quercetin), had higher bone mineral density measurements than those who did not drink tea. Quercetin in the tea might be responsible for the prevention of osteoporosis ${ }^{115}$.

\section{Peptic Ulcer:}

Quercetin seems to play a very important role in the prevention and treatment of peptic ulcer. It acts by promoting mucus secretion, thereby serves as gastroprotective agent. Apparently, many peptic ulcers can be caused by infectious bacteria, known as Helicobacter pylori. Quercetin has been shown to inhibit the growth of this bacterium in in-vitro studies ${ }^{\mathbf{1 1 6 , 1 1 7}}$.

\section{Prostatitis:}

In a prospective double-blind placebo controlled study, quercetin was found to be helpful in category III chronic prostatitis (non bacterial chronic prostatitis and prostodynia). Thirty men with this disorder received either placebo or 500 mg of quercetin twice daily for one month. Significant improvement was achieved in treated group, as measured by the National Institute of Health Chronic Prostatitis score ${ }^{\mathbf{1 1 8}}$. In a follow up unblind open study, additional men received the same amount of quercetin for one month, but this time quercetin was combined with bromelain and papain, which may enhance its absorption. In this study $82 \%$ achieved a minimum 25\% improvement score.

\section{Viral infections:}

The antiviral effect of Flavonoid was shown in a study conducted by Wang et $\mathbf{a l}^{\mathbf{1 1 9}}$. Some of the 
viruses reported to be affected by Flavonoids are herpes simplex virus, respiratory syncitial virus and adenovirus. Quercetin was reported to exhibit both anti-infective and antireplicative abilities. By far most of the studies were performed in vitro and little is known about the antiviral effect of flavonoids in vivo. There is some evidence that flavonoids in their glycon form seem to be more inhibitory effect on rotavirus infectivity than flavonoids in their aglycon form ${ }^{\mathbf{1 2 0}}$. Because of the worldwide spread of HIV, since 1980s, the investigations of the antiviral activity of flavonoids have mainly focused on HIV. The discovery and the development of flavonoids as anti-HIV agents have expanded in the past two decades. Most of the studies focused on the inhibitory activity of reverse transcriptase or RNA directed DNA polymerase but antiintegrase and antiprotease activities were also reported. Flavonoids have mainly been studied in vitro experiments; therefore no clear contribution of flavonoids to the treatment of HIV infected patients has yet been shown ${ }^{121,122}$.

\section{PREPARATION AND DOSAGES:}

The average diet can supply 15 to $40 \mathrm{mg}$ of quercetin per day from fruit and vegetable consumption. Increasing quercetin intake for general health reasons can be accomplished by simply eating more vegetables and fruit. However, as most people are confronted with the reality of not being able to maintain an adequate intake of bioflavonoid from food sources, extra quercetin can be obtained from dietary supplements. For therapeutic purposes such as allergy management, anti-inflammatory treatment, and disease treatment, higher dosages of quercetin are usually prescribed. Therapeutic dosages can range from 250 to $500 \mathrm{mg}$ three times per day. Quercetin is available in the form of capsules $(250 \mathrm{mg}, 300 \mathrm{mg}$, and $500 \mathrm{mg}$ ) and tablets (50 mg, $250 \mathrm{mg}$, and 500mg). Recommended adult dosages of quercetin vary depending on the health condition being treated. For allergic conditions, 250-600 mg per day in divided doses and for chronic hives, 200-400 mg thrice daily quercetin is recommended ${ }^{\mathbf{1 2 3}}$.

\section{FUTURE IMPLICATIONS:}

Various cohort studies indicated an inverse association between Flavonoids intake (Quercetin) and coronary heart disease mortality. These studies are promising and indicate that flavonoids may be useful food compounds. Flavonoids have received much attention in the literature over the past 10 years and a variety of potential beneficial effects have been elucidated. However, most of the studies have been conducted in vitro studies; therefore, it is difficult to draw definite conclusion about the usefulness of flavonoids in the diet. Furthermore, insufficient methods are available to measure oxidative damage in vivo and the measurement of objective endpoints remains difficult. Although recently some studies ${ }^{124,125,126}$ have been conducted on absorption and excretion of flavonols including quercetin but there is a need to improve analytic techniques to allow collection of more data in this aspect. Data on the long-term consequences of chronic quercetin ingestion are especially scarce. To conclude, invivo studies could be performed to give a hopeful picture for the future. Currently, the intake of fruit, vegetables, and beverages (e.g., tea and moderate amounts of red wine) containing quercetin is recommended, although it is too early to make recommendations on daily quercetin intakes.

\section{REFERENCES:}

1. Middleton EJ. Effect of plant flavonoids on immune and inflammatory cell functions. Adv Exp Med Biol 1998;439:175-182.

2. De Groot H, Rauen U. Tissue injury by reactive oxygen species and the protective effects of flavonoids. Fundam Clin Pharmacol 1998;12:249-55.

3. Narayana K Raj, Reddy M Sripal, Chaluvadi MR, Krishna DR. Bioflavonoids classification, pharmacological, Biochemical effects and therapeutic potential. Indian Journal of pharmacology 2001;33:2-16.

4. Molecular structures of major classes of flavonoids retrieved from http:/www.emolecules.com/cgi-bin/search

5. Havsteen B. Flavonoids: A class of natural products of high pharmacological potency. Biochem Pharmacol 1983;32:1141-8.

6. Middleton E. The Flavonoids. Trends Pharmacol Sci 1984;5:335-8.

7. Murphy Karen J, Chronopoulos Andriana K, Singh I, el al. Dietary flavanols and procyanidin oligomers from cocoa (Theobroma cacao) inhibit platelet function. American Journal of Clinical Nutrition 2003;77(6):1466-73.

8. Moskuag JO, Carlson H, Myhrstad M, et al. Molecular Imaging of the biological effects of Quercetin and Quercetin-rich foods. Mechanism of Ageing and Development 2004;125:315-24. 
9. De Groot H. Reactive oxygen species in tissue injury. Hepatogastroentrology 1994:41:328-32.

10. Grace PA. Ischemia-reperfusion injury. $\mathrm{Br} J$ surg 1994;81:637-47.

11. Halliwell B. How to characterize an antioxidant: an update. Biochem soc symp 1995;61:73-101.

12. Bahorun T, Soobrattee MA, LuximonRamma V, Aruoma OI. Free Radicals and Antioxidants in Cardiovascular Health and Disease. Internet Journal of Medical Update 2006 Jul-Dec;1(2): http://www.geocities.com/agnihotrimed/pap er05 jul-dec2006.htm

13. Wegener T, Fintelmann V. Flavonoids and Bioactivity. Wein Med Wochem Schr 1999;149:241-7.

14. Ares JJ, Outt PE. Gastroprotective agents for the prevention of NSAID- induced gastropathy. Curr Pharm Des 1998;4:7-36.

15. Santos AC, Vyemura SA, Lopes JL, et al. Effect of naturally occurring flavonoids on lipid peroxidation and membrane permeability transition in mitochondria.Free Radic Biol Med 1998;24:1455-61.

16. Halliwell B. Free radicals, antioxidants and human disease: curiosity, cause or constipation? Lancet 1994;344:721-4.

17. Fraga CG, Mactino US, Ferraro GE, et al. Flavonoids as antioxidants evaluated by in vitro and insitu liver chemiluminescence. Biochem Med Metabol BioI 1987;36:717-20.

18. Kerry NL, Abbey M. Red wine and fractionated phenolic compounds prepared from red wine inhibits low density lipoprotein oxidation in vitro. Atherosclerosis 1997;135:93-102.

19. Shoskes DA. Effect of bioflavonoid quercetin and curcumin on ischaemic renal injury: a new class of renoprotective agent. Transplantation 1998;66:147-52.

20. Huk I, Brovkovych V, Nanobash VJ, et al. Bioflavonoid quercetin scavenges superoxide and increase nitric oxide concentration in ischemia-reperfusion injury: an experimental study. $\mathrm{Br} J$ surg 1998;85:1080-5.

21. Shutenko Z, Henry Y, Pinard E, et al. Influence of antioxidant quercetin in vivo on the level of nitric oxide determined by electron paramagnetic resonance in rat brain during global ischemia and reperfusion. Biochem Pharmacol 1990;57:199-208.

22. Van Acker SA, Tromp MN, Haenen GR, et al. Flavonoids as scavengers of nitric oxide radical. Biochem Biophys Res Commun 1995;214:755-9.

23. Santrueza J, Valdes J, campos R, et al. Changes in xanthine dehydrogenase/xanthine oxidase ratio in the rat kidney subjected to ischemia-reperfusion stress: Preventive effect of some flavonoids. Res commun chem. Pathol pharmacol 1992;78:211-8.

24. Chang WS, Lee YJ, Leu FJ, Chiang HC. Inhibitory effects of Flavonoids on xanthine oxidase. Anticancer Res 1993;13:2165-70.

25. Iio M, Ono Y, kai S, Fukumoto M. Effects of flavonoids on xanthine oxidase as well as on cytochrome $\mathrm{C}$ reduction by milk xanthine oxidase. J Nutr Sci Vitaminol (Tokyo) 1986;32:635-42.

26. Friesenecker B, Tsai AG, Allegra C, Intaglietta M. Oral administration of purified micronized flavonoid fraction suppresses leukocyte adhesion in ischemia reperfusion injury: in vivo observation in the hamster skin fold. Int $J$ microcir clin Exp 1994; 14:50-5.

27. Silvia Mandel, Orly Weinreb, Tamar Amit, et al. Cell signaling pathways in the neuroprotective actions of the green tea polyphenol (-)-epigallocatechin-3-gallate: implications for neurodegenerative diseases Journal of Neurochemistry 2004;88:155569.

28. Calamia KT. Current and future use of antiTNF agents in the treatment of autoimmune, inflammatory disorders. Adv. Exp. Med. Biol 2003;528:545-9.

29. Taylor PC, Williams RO, Feldmann M. Tumour necrosis factor alpha as a therapeutic target for immune-mediated inflammatory diseases. Curr. Opin. Biotechnol. 2004;15:557-63.

30. Aggarwal BB. Tumour necrosis factor receptor associated signaling molecules and their role in activation of apoptosis. JNK and NF-kappa B. Ann. Rheum. Dis. 2000;59:616.

31. Aggarwal BB, Samanta A, Feldmann M. TNF- $\alpha$, p. 413. In J. J. Oppenheim, M. Feldman, S. K. Durum, T. Hirano, J. Vilcek, and N. A. Nicola (ed.) Cytokine reference, Vol 1, Academic Press, San Diego, Calif. 2001.

32. Wajant H, Henkler F, Scheurich P. The TNF-receptor-associated factor family: scaffold molecules for cytokine receptors, kinases and their regulators. Cell. Signal. 2001;13:389-400. 
33. Kaneuchi M, Sasaki M, Tanaka Y, et al. Quercetin regulates growth of Ishikawa cells through the suppression of EGF and cyclin D1. Int J Oncol. 2003 Jan;22(1):159-64.

34. Nishino $H$, Naitoh E, Iwashima A, et al. Quercetin interacts with calmodulin, a calcium regulatory protein. Experientia 1984;40:84-5.

35. Buss WW, Kopp DE, Middleton E. Flavonoids modulation of human neutrophil function. Allergy Clin Immunol 1984;73:801-9.

36. Havsteen B. Flavonoids, a class of natural products of high pharmacological potency. Biochemical pharmacology 1983;32(7):14148.

37. Otsuka H. Histochemical and functional characteristics of metachromatic cells in the nasal epithelium in allergic rhinitis. Studies of nasal scrapings and their dispersed cells. $J$ Allergy Clin Immunol 1995;96:528-36.

38. Fox CC, Wolf EJ, Kagey-Sobotka A, et al. Comparison of human lung and intestinal mast cells. $J$ Allergy Clin Immunol 1988;81:89-94.

39. Pearce FL, Befus AD, Bienenstock J. Mucosal mast cells III. Effects of quercetin and other flavonoids on antigen induced histamine secretion from rat intestinal mast cells. J Allergy Clin Immunol 1984;73:81923.

40. Middleton E, Drzewiecki G, Krishnarao D. Quercetin: an inhibitor of antigen induced human basophil histamine release. Journal of Immunology 1981;127 (2):546-50.

41. Bennett JP, Gomperts BD, Wollenweber E. Inhibitory effects of natural flavonoids on secretion from mast cell and neutrophils. Arzneim. Forsch/Drug Res. 1981;31(3):4337.

42. Middleton E, Drzewiecki G. Naturally occurring flavonoids and human basophil histamine release. Int Arch Allergy Appl Immun 1985;77:155-7.

43. Yoshimoto T, Furukawa M, Yamamoto S, et al. Flavonoids: potent inhibitors of arachidonate 5-lipoxygenase. Biochemical and biophysical research communications 1983;116(2):612-18.

44. Della Loggia R, Ragazzi E, Tubaro A et al. Anti-inflammatory activity of Benzopyrones that are inhibitors of cyclo and lipoxygenase. Pharmacological research communications 1988;20 (suppl V):91-94.

45. Middleton E, Suresh A. Quercetin inhibits lipopolysaccharide induced expression of endothelial cell intracellular adhesion molecule-1. Int Arch Allergy Immunol 1995; 107:435-6.

46. Afanas'ev IB, Dorozhko AI, Brodskii $\mathrm{AV}$, et al. Chelating and free radical scavenging mechanisms of inhibitory action of rutin and quercetin in lipid peroxidation. Biochemical 1989;38(11):1763-69.

47. Ferrali M, Signorini C, Caciotti B, et al. Protection against oxidative damage of erythrocyte membrane by the flavonoid quercetin and its relation to iron chelating activity. FEBS Lett 1997;416:123-9.

48. Sorata Y, Takahama U, Kimura M. Protective effect of quercetin and rutin on photosensitized lysis of human erythrocytes in the presence of hematoporphyrin. Biochim Biophys Acta 1984;799:313-7.

49. Manach C, Donavan J. Pharmacokinetics and metabolism of Dietary Flavonoids in humans. Free Radical Research 2004;38:771-785.

50. Hollman PC, de Vries JH, Van Leeuwen $\mathrm{SD}$, et al. Absorption of dietary quercetin glycosides and quercetin in healthy ileostomy volunteers. Am J Clin Nutr 1995;62:1276-1282.

51. Murota K, Terao J. Antioxidative Flavonoid quercetin: Implication of its intestinal absorption and metabolism. Arch Biochem Biophys 2003;417:12-17.

52. Lesser $\mathrm{S}$, Cermak $\mathrm{R}$, Wolffram $\mathrm{S}$. Bioavailability of quercetin in pigs is influenced by the dietary fat content. J Nutr. 2004 Jun;134(6):1508-11.

53. Taussig SJ. The mechanism of the physiological action of bromelain. Medical Hypothesis 1980;6:99-104.

54. Ako H, Cheung AHS, Matsuura PK. Isolation of a fibrinolysis activator from commercial bromelain. Arch. Int. Pharmacodyn. 1981;284:157-67.

55. Young JF, Nielsen SE, Haraldsdottir J, et al. Effect of fruit juice intake on urinary quercetin excretion and biomarkers of antioxidative status. Am J Clin Nutr 1999;69:87-94.

56. Formica JV, Regelson W. Review of the biology of quercetin and related bioflavonoid. Food Chem Toxicol 1995;33:1061-80.

57. Ertrurk E, Hatcher JF, Pamukeu AM. Bracken fern. Carcinogenesis and quercetin (abstr). Fed Proc 1984;43:2344. 
58. Starvic B. Quercetin in our diet: from potent Mutagen to probable anticarcinogen. Clin Biochem. 1984;43:2344.

59. Dunnick JK, Hailey JR. Toxicity and carcinogenicity studies of quercetin, a natural component of foods. Fundam Appl Toxicol 1992;19:423-31.

60. Bjeldanes LF, Chang GW. Mutagenic activity of quercetin and related compounds. Science 1997:577-8.

61. Zhu BT, Ezell ET, Liehr JG. Catechol-omethyl transferase catalysis rapid $\mathrm{O}$ methylation of mutagenic flavonoids. Metabolic inactivation as a possible reason for their lack of carcinogenicity in vivo. $J$ Biol Chem 2001;269:292-9.

62. Kato K, Mori H, Fujii M, et al. Lack of promotive effect of quercetin on methylazoxymethanol acetate carcinogenesis in rats. $J$ Toxicol Sci 1984;9:319-25.

63. Plakas SM, Lee TC, Wolke RE. Absence of overt toxicity from feeding the flavonol, quercetin, to rainbow trout (Salmo gairdneri). Food Chem Toxicol 1985;23:1077-80.

64. Knekt P, Jarvinen R, Seppanen R, et al. Dietary flavonoids and the risk of lung cancer and other malignant neoplasms. Am J Epidemiol 1997;146:223-30.

65. Beyer G, Melzig MF. Effects of selected flavonoids and caffeic acid derivatives on hypoxanthine-xanthine oxidase-induced toxicity in cultivated human cells. Planta Med 2003;69:1125-9.

66. Underger U, Aiding S, Basaran AA, Basaran $\mathrm{N}$. The modulating effects of quercetin and rutin on the mitomycin $\mathrm{C}$ induced DNA damage. Toxicol Lett 2004;151:143-9.

67. Stoewsand GS, Anderson JL, Boyd JN, Hrazdina G. Quercetin: a mutagen, not a carcinogen in Fischer rats. J Toxicol Environ Health 1984;14:105-14.

68. Okamoto T. Safety of quercetin for clinical application (Review). Int J Mol Med. 2005 Aug;16(2):275-8.

69. Miniscalco A, Lundahl J, Regardh CG. Inhibition of dihydropyridine metabolism in rat and human liver microsomes by flavonoids found in grapefruit juice. $J$ Pharmacol Exp Ther 1992;261:1195-9.

70. Bailey DG, Malcolm J, Arnold O, Spence JD. Grapefruit juice-drug interactions. $\mathrm{Br} J$ Clin Pharmacol 1998;46:101-10.

71. Schubert W, Cullberg G, Edgar B, Hedner T. Inhibition of 17 beta-estradiol metabolism by grapefruit juice in ovariectomized women. Maturitas 1994;20:155-63.

72. Weber A, Jager R, Borner A, et al. Can grapefruit juice influence ethinylestradiol bioavailability? Contraception 1996;53:417.

73. Schubert W, Eriksson U, Edgar B, et al. Flavonoids in grapefruit juice inhibit the in vitro hepatic metabolism of 17 betaestradiol. Eur J Drug Metab Pharmacokinet 1995;3:219-24.

74. Ioannides-Demos LL, Christophidis N, Ryan $\mathrm{P}$, et al. Dosing implication of a clinical interaction between grapefruit juice and cyclosporine and metabolite concentrations in patients with autoimmune diseases. $J$ Rheumatol 1997;24:49-54.

75. Choi JS, Choi BS, Choi KE. Effect of quercetin on the pharmacokinetics of oral cyclosporine. Am J Health Syst Pharm 2004;61:2406-9.

76. Hilliard JJ, Krause HM, Bersstein JJ, et al. A comparison of active site binding of 4quinolones and novel flavone gyrase inhibitors to DNA gyrase. Adv Exp Med Biol.1995;390:59-69.

77. Wang Y-H, Chao P-D L, Hsiu S-L, et al: Lethal quercetin-digoxin interaction in pigs. Life Sci 2004;74:1191-7.

78. Miean KH, Mohamed S. Flavonoids (Myricitin, Quercetin, Kaempferol, Luteolin and Apigenin) contents of edible tropical plants. J Agric Food Chem 2001;49 (6):3106-12.

79. Mangels AR, Holden JM, Beecher GR, et al. Caretenoide contents of fruits and vegetables: an evaluation of analytical data. Am Diet. Assoc 1993;93:284-296.

80. Häkkinen S, Kärenlampi S, Heinonen $M$, et al. Content of the flavonols quercetin, myricetin, and kaempferolin 25 edible berries. J Agric Food Chem. 1999 Jun;47(6):2274-9.

81. Herrmann K. Flavonols and flavones in food plants: a review. Journal of Food Technology 1976;11:433-448.

82. Hertog MGL, Hollman PCH. Potential health effects of the dietary flavonol quercetin. Euro. J. of Clin. Nutr 1996;50:6371.

83. Patil BS, Pike LM, Yoo KS. Variation in the quercetin content in different colored onions (Allium cepa L.). Journal of the American Horticulture Society 1995;120 (6):909-13.

84. Lombard KA, Geoffriau E, Peffley E. Flavonoid quantification in onion (Allium 
cepa L.) by spectrophotometric and HPLC analyses. Hort Science 2002;37(4):682-5.

85. Patil BS, Pike LM. Distribution of quercetin content in different rings of various colored onion (Allium cepa L.) cultivars. Journal of Horticultural Sciences 1995;70(4):643-50.

86. Lombard KA. Investigation of the flavonol quercetin in onion (Allium cepa L.) by highperformance liquid chromatography (HPLC) and spectrophotometric methodology. M.S. Thesis. Journal of Food Composition and Analysis 2005;18:635-45.

87. Harnly JM, Doherty RF, Beecher GR, et al. Flavonoid content of U.S. fruits, vegetables, and nuts. J Agric Food Chem. 2006 Dec 27;54(26):9966-77.

88. Thornhill SM, Kelly AM. Natural treatment of perennial allergic rhinitis. Alt Med Rev. 2000;5(5):448-54.

89. Kempuraj D, Castellani ML, Petrarca C, et al. Inhibitory effect of quercetin on tryptase and interleukin- 6 release, and histidine decarboxylase mRNA transcription by human mast cell-1 cell line. Clin Exp Med. 2006 Dec;6(4):150-6.

90. Rigano D, Formisano C, Basile A, et al. Antibacterial activity of flavonoids and phenylpropanoids from Marrubium globosum ssp. libanoticum. Phytother Res. 2006 Dec 21; [Epub ahead of print].

91. Kim HP, Mani I, Iversen L, Ziboh VA. Effects of naturally-occurring flavonoids and bioflavonoids on epidermal cyclooxygenase and lipoxygenase from guinea-pigs. Prostaglandins Leukot Essent Fatty Acids 1998;58:17-24.

92. Yoshimoto T, Furukawa M, Yamamoto S, et al. Flavonoids: potent inhibitors of arachidonate 5-lipoxygenase. Biochem Biophys Res Commun 1983;116:612-8.

93. Hanninen, Kaartinen K, Rauma AL, et al. Antioxidants in vegan diet and rheumatic disorders. Toxicology. 2000;155(1-3):45-53.

94. Muhammad A, Soobrattee, Bahorun T, Okezie I Aruoma. Chemopreventive actions of plyphenolic compounds in cancer. BioFactors 2006;27:19-35.

95. Caltagirone S, Rossi C, Poggi A, et al. Flavonoids apigenin and quercetin inhibit melanoma growth and metastatic potential. Int J Cancer 2000;87:595-600.

96. Heloísa D, Coletta Francescato, Terezila M, et al. Protective effect of quercetin on the evolution of cisplatin -induced acute tubular necrosis. Kidney \& Blood Pressure Research 2004;27:148-158
97. Fotsis T, Pepper MS, Aktas E, et al. Flavonoids, dietary-derived inhibitors of cell proliferation and in vitro angiogenesis. Cancer Res 1997;57:2916-21.

98. Fan TP, Jaggar R, Bicknell R. Controlling the vasculature: angiogenesis, antiangiogenesis and vascular targeting of gene therapy. Trends Pharmacol Sci 1995;16:5766.

99. Paper DH. Natural products as angiogenesis inhibitors. Planta Med 1998;64:686-95.

100. Oikawa T, Shimamura M, Ashino H, et al. Inhibition of angiogenesis by staurosporine, a potent protein kinase inhibitor. J Antibiot (Tokyo) 1992;45:1155-1160.

101. Varadkar P, Dubey P, Krishna M, et al. Modulation of radiation-induced protein kinase $\mathrm{C}$ activity by phenolics. J. Radiol. Prot. 2001;21:361-70.

102.Hertog MG, Kromhout D, Aravanis C, et al. Flavonoid intake and long-term risk of coronary heart disease and cancer in the seven countries study. Arch Intern Med 1995;155:381-6.

103.Hertog MG, Feskens EJ, Hollman PC, et al. Dietary antioxidant flavonoids and risk of coronary heart disease: the Zutphen Elderly Study. Lancet 1993;342:1007-11.

104.Arai Y, Watanabe S, Kimira M, et al. Dietary intakes of flavonols, flavones and isoflavones by Japanese women and the inverse correlation between quercetin intake and plasma LDL cholesterol concentration. $J$ Nutr 2000;130:2243-50.

105.Osman HE, Maalej N, Shanmuganayagam D, Folts JD. Grape juice but not orange or grapefruit juice inhibits platelet activity in dogs and monkeys. J Nutr 1998;128:230712.

106.Tzeng SH, Ko WC, Ko FN, Teng CM. Inhibition of platelet aggregation by some flavonoids. Thromb Res 1991;64:91-100.

107.Hubbard GP, Wolffram S, de Vos R, et al. Ingestion of onion soup high in quercetin inhibits platelets aggregation and essential components of collagen-stimulated platelet activation pathway in man: A pilot study. $\mathrm{Br}$ J Nutr. 2006 Sep;96(3):428-8.

108. Costantino L, Rastelli G, Gamberini MC, et al. 1-Benzopyran -4-one antioxidant as aldose reductase inhibitors. Med Chem 1999;42:1881-93.

109. Cai J, Nelson KC, Wu M, et al. Oxidative damage and protection of the RPE. Prog Retin Eye Res. 2000;19(2):205-21. 
110.Head KA. Natural therapies for ocular disorders. Part 1: diseases of the retina. Alt Med Rev. 1999 Oct;5(4):342-59.

111. Heo HJ, Kim DO, Choi SJ, et al. Apple Phenolics Protect in Vitro Oxidative Stressinduced Neuronal Cell Death. J Food Sci 2004;69(9):S357-60.

112.Singh A, Naidu PS, Kulkarni SK. Reversal of aging and chronic ethanol-induced cognitive dysfunction by quercetin.a bioflavonoid. Free Radic Res 2003;37(11):1245-52.

113.Singh A, Pattipati S .Quercetin potentiates L-Dopa Reversal of Drug Induced Catalepsy in Rats: Possible COMT/MAO inhibition: Pharmacology 2003;68:81-88.

114.Naidu PS, Kulkarni SK. Quercetin, a bioflavonoid, reverses haloperidol induced catalepsy. Methods find Exp Clin Pharmacol. 2004 Jun;26(5):323-6.

115.Hegarty VM, May HM, Khaw KT. Tea drinking and bone mineral density in older women. Am J Clin Nutr 2000;71:1003-7.

116. Martin MJ, La-Casa C, Alarcon-de-LaLastra C, et al. Antioxidant mechanism involved in gastro protective effects of quercetin. Z Naturforsch [C].1988;53:82-8.

117. Alarcon de La Lastra C, Martin MJ, Motilve V. Antiulcer and gastroprotective effects of quercetin: a gross and histological study.Pharmacol.1994;48:56-62.

118. Shoskes DA, Zeitlin SI, Shahed A, Rajfer J. Quercetin in men with category III chronic prostatitis: a preliminary prospective, double-blind, placebo-controlled trial. Urology. 1999;54(6):960-3.

119. Wang HK, Xia Y, Yang ZY, et al. Recent advances in the discovery and development of flavonoids and their analogues as antitumor and anti-HIV agents. Adv Exp Med Biol 1998;439:191-225.

120.Bae EA, Han MJ, Lee M, Kim DH. In vitro inhibitory effect of some flavonoids on rotavirus infectivity. Biol Pharm Bull 2000;23:1122-4.

121. Vlietinck AJ, De Bruyne T, et al. Plantderived leading compounds for chemotherapy of human immunodeficiency virus (HIV) infection. Planta Med 1998;64:97-109.

122.Ng TB, Huang B, Fong WP, Yeung HW. Anti-human immunodeficiency virus (antiHIV) natural products with special emphasis on HIV reverse transcriptase inhibitors. Life Sci 1997;61:933-49.

123. Werbach MR. Nutritional Influences on Illness. 2nd ed. Tarzana, Calif: Third Line Press. 1993.

124. Mullen W, Edwards CA, Crozier A. Absorption, excretion and metabolite profiling of methyl-, glucuronyl-, glucosyland sulpho-conjugates of quercetin in human plasma and urine after ingestion of onions. Br J Nutr. 2006 Jul;96(1):107-16.

125.Aziz AA, Edwards CA, Lean ME, Crozier A. Absorption and excretion of conjugated flavonols, including quercetin-4'-O-betaglucoside and isorhamnetin-4'-O-betaglucoside by human volunteers after the consumption of onions. Free Radic Res. 1998 Sep;29(3):257-69.

126.McAnlis GT, McEneny J, Pearce J. Absorption and antioxidant effects of quercetin from onions, in man. Eur J Clin Nutr. 1999 Feb;53(2):92-6. 